\title{
Design Construction and Performance Test of a Low Cost Subsonic Wind Tunnel
}

\author{
Md. Arifuzzaman ${ }^{1}$, Mohammad Mashud $^{2}$ \\ ${ }^{1,2}$ Department of Mechanical Engineering, Khulna University of Engineering \& Technology, Khulna, \\ Bangladesh
}

\begin{abstract}
Wind tunnel is a device, by artificially producing airflow relative to a stationary body that measures aerodynamic force and pressure distribution to simulate with actual conditions. Wind Tunnels offer a rapid, economical, and accurate means for aerodynamic research. The most important aspect of wind tunnels is their ability to accurate recreate the full complexity of full fluid flow. In the current study, a low cost subsonic wind tunnel is designed, constructed and its performance is tested. The main focuses were to reduce the cost of construction and to erect it in a laboratory room. The cross section of the wind tunnel is of square type with dimension $0.90 \mathrm{~m} \times 0.90 \mathrm{~m}$ and the length of the section is $1.35 \mathrm{~m}$. The overall length of the tunnel is about 7.35 $m$ which can be erected in a laboratory room. After testing the performance of the tunnel it is found that the maximum wind velocity inside the wind tunnel test section is about $28 \mathrm{~m} / \mathrm{s}$ and the velocity profile along the height and width of the test section is almost linear in nature excluding the approximately $12 \%$ allowance in four side walls where boundary layer if formed. The constructed wind tunnel was conformed to the design and can be used for different test in the field of aerodynamics.
\end{abstract}

Keywords —Subsonic Wind Tunnel, Low Cost, Test Section, Aerodynamics, Fluid Flow, Velocity Profile

\section{INTRODUCTION}

Wind engineering is a field that has been evolving over centuries. A large portion of wind engineering today relies directly or indirectly on wind tunnels. Wind tunnels are used for a variety of different reasons such as their ability to test prototypes early in design cycles, or because of their ability to record a large amount of data [1]. Aerodynamicists use wind tunnels to test models of proposed aircraft since the flow conditions can be carefully controlled in the tunnel which affect the forces on the aircraft.

Experimental information useful for solving aerodynamic problems may be obtained in a number of ways: from flight tests; drop tests; rocket sleds; water tunnels; whirling arms; shock tubes; water tables; rocket flights; flying scale models; ballistic ranges; and subsonic, near-sonic, transonic, super-sonic, and hypersonic wind tunnels. Each device has its own sphere of superiority, and no one device can be called "best" [2]. In a society that is growing dependent on computers and always moving towards new technologies, the use of wind tunnels to solve aerodynamic problems may seem obsolete. But the use of wind tunnels to solve both basic and complex aerodynamic problems is still needed today. Unlike computers which produce mostly quantitative data, wind tunnels provide unique flow visualization that can find critical problems and solutions not seen in the pure numbers. With their ability to combine both types of data, wind tunnels are a critical instrument in the quick and thorough design process of anything that involves fluid dynamics. One of the most important parts of a wind tunnel is the flow visualization it provides. Sure lift, drag and efficiency can all be calculated with complex equations.

The versatility and tangibility of a wind tunnel is what makes it such an important part of aerodynamic research. Being such an important part of aerodynamic research, it is important to continue to promote wind tunnel testing [3]. No single wind tunnel is adequate for all possible aerodynamics tests. In general, wind tunnels can be divided into four broad categories by their speed ranges: subsonic with a maximum Mach number of up to 0.4 ; transonic with a maximum Mach number to 1.3; supersonic with a maximum Mach number up to 4.0 to 5.0; and hypersonic with a Mach number 5.0 or higher [2].

In this project, the ultimate goal is to research, design, build and evaluate a real wind tunnel in order to more fully understand basic concepts of aerodynamics and recognize the capabilities and importance of wind tunnels in solving practical engineering problems. Another focus on this research is to minimize the cost of construction. 


\section{DESIGN METHODOLOGY}

The wind tunnel is made of several distinct sections, the settling chamber, the contraction cone, the test/working section, the diffuser and the fan. Several considerations have to be made in order to achieve a wind tunnel with the wanted properties [10]. The main design criteria are listed in the table below:

$>$ Open circuit wind-tunnel.

$>$ Good flow quality (mean flow variation, turbulence intensities \& temperature variation).

$>$ Contraction ratio, $\mathrm{CR}$, of 8 .

Test section is square and the maximum test section length possible in the available space.

Maximum flow speed in the test section of $40 \mathrm{~m} / \mathrm{s}$.

$>$ Low noise level.

$>$ Low cost.

\section{Test Section}

The first step in wind tunnel design is defining a priori the test chamber criteria which are dimensions, shape and desired air velocity. In this case, a square testing chamber with a $0.9 \mathrm{~m}$ side was used with an air velocity of $40 \mathrm{~m} / \mathrm{s}$. The test chamber length has to be in the range of $0.5-3$ times its hydraulic diameter [2]. This choice takes into account that the air flow exiting the nozzle needs 0.5 times the hydraulic diameter to become almost uniform.

Moreover, a long test chamber (more than 3 times the equivalent hydraulic diameter) could increase boundary layer thickness causing the boundary layer to detach at the test chamber exit. So, in this study the length of the testing chamber was set to 1.3 times the hydraulic diameter of the testing section. The test section length becomes about $1.35 \mathrm{~m}$. The test chamber also has flanges and windows to allow sample observations and introduce measuring tools. Fig. 1 shows AutoCAD design of a test chamber.

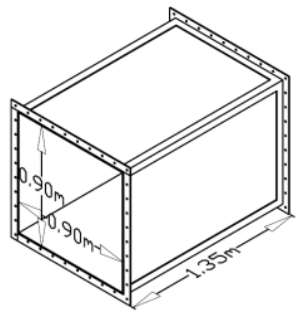

Figure: 1 Designed test section

\section{Contraction Cone}

Knowing the contraction cone exit cross-section dimensions and shape, those of its inlet cross section must be determined. The contraction cone area ratio should be 'as large as possible', to reduce the total-pressure loss through the screens mounted between the settling chamber and the cone. Normally, the contraction cone inlet/outlet cross-section area ratio should be in the range 6 - 10 [14]. Area ratios greater than 10 lead to excessive inlet dimensions while area ratios less than 6 lead to high pressure loss through the screens. In this study, an area ratio of 8 was chosen.

The contraction exit length is sensitive to the required length in the test section for a uniform velocity profile. For a contraction ratio of 8 , the contraction section length varies from $0.15-1$ times the inlet radius, while the test section settling chamber length varied from 1.5 to 0.5 of the exit radius. The length of the contraction is found to be $0.38 \mathrm{~m}$. Fig. 2 shows the designed contraction cone with settling chamber.

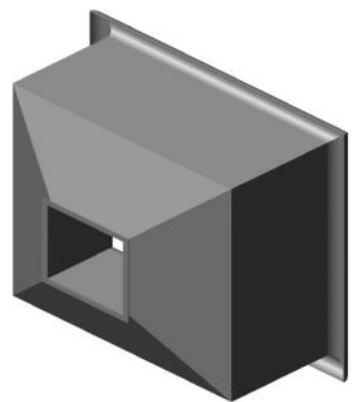

Figure: 2 Contraction cone with settling chamber 


\section{Diffuser}

The diffuser of a wind tunnel usually extends from downstream end of the test section to the fan. Its main purpose is to reduce velocity in the shortest possible distance to minimize losses. [3] Area ratio of the diffuser should be less than 2.5 and diffuser angle should be $5^{\circ}-7^{\circ}$ for controlling flow separation. [4] According to these conditions, the diffuser outlet diameter is found to be $122 \mathrm{~cm}$. The minimum length of diffuser can be found from equation given below:

$$
\vartheta_{e}=\arctan \left(\frac{1}{2} \frac{\sqrt{A_{R}}-1}{L / D_{h 1}}\right)
$$

Where, $D_{h l}$ is the inlet section's hydraulic diameter and $\vartheta_{e}$ is the half of the included angle of the diffuser cone.

Solving for $\mathrm{L}$ the minimum length of the diffuser is found to be $2.34 \mathrm{~m}$. By adjustment with area ratio and the length of the diffuser is found $3.7 \mathrm{~m}$ which satisfy the above criteria. The AutoCAD design of the diffuser is shown in Fig. 3.

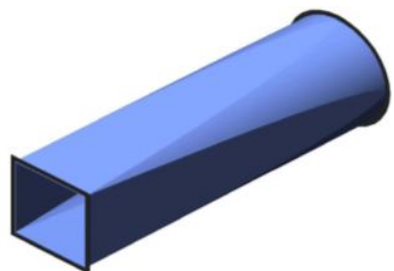

Figure: 3 Square inlet and circular outlet diffuser section

\section{Settling Chamber}

Before the contraction cone there is a settling chamber with a constant cross-sectional area. The aim of a settling chamber which contains honeycombs and screens is to reduce the flow turbulence before it enters the cone. The settling chamber cross-sectional area matches the dimensions of contraction cone inlet diameter. A settling chamber length of 0.5 times the inlet diameter is often used. Thus, the length of the settling chamber becomes $1.105 \mathrm{~m}$.

\section{Honeycomb}

A honeycomb with its cells aligned in the flow direction is able to reduce fluctuating variations in transverse velocity. The honeycomb has little effect on stream-wise velocity due to the fact that the pressure drop through a honeycomb is small [15]. The primary reason to use a honeycomb is that, with a sufficient length of about 10 cell diameters, it is a very effective flow straightening device. The relatively low pressure drop of a honeycomb makes it rather ineffective in reducing non-uniformities or fluctuations in the stream-wise component but it is very effective in reducing cross-stream components [16].

In the honeycomb design procedure, its length $\left(L_{h}\right)$, cell hydraulic diameter $\left(D_{h}\right)$, and the porosity $\left(\beta_{h}\right)$ are key factors [12]. Honeycomb porosity is defined as the ratio of actual flow cross-section area over the total cross-section area.

$$
\beta_{h}=\frac{A_{\text {flow }}}{A_{\text {total }}}
$$

Two main criteria have to be verified in wind tunnel honeycomb design. The first one is;

$$
6 \leq \frac{L_{h}}{D_{h}} \leq 8
$$

and the second one is;

$$
\beta_{h} \geq 0.8
$$

For optimum benefit, honeycombs should be 6-8 cell diameters thick and cell size should be on the order of about 150 cells per settling chamber diameter [5]. The parameters of the honeycomb in this study are shown in the Table 1 below;

Table: 1 Parameters of honeycomb in this study

\begin{tabular}{|l|l|l|l|}
\hline Parameters & Symbols & Value & Units \\
\hline Cell hydraulic diameter & $D_{h}$ & 2.12 & $\mathrm{~cm}$ \\
\hline Length of honeycomb & $L_{h}$ & 12 & $\mathrm{~cm}$ \\
\hline Number of cells & $\mathrm{N}$ & 38000 & \\
\hline Length to diameter ratio & $L_{h} / D_{h}$ & 6 & \\
\hline Honeycomb porosity & $\beta_{h}$ & 0.8 & \\
\hline
\end{tabular}




\section{Screens}

It is well known that screens mainly reduce stream-wise velocity fluctuations, with little effect on flow direction. Moreover, it has been demonstrated that a series of screens with different mesh qualities (coarse, medium and fine) is more efficient than only one fine mesh screen. To be effective in reducing turbulence a screen must have porosity in the range $0.58-0.8$ [15].

Screen porosity values over 0.8 are not suitable for good turbulence control, while values below 0.58 lead to flow instability. Screens could also be installed on a removable frame for cleaning and maintenance. Since the screens are inside the settling chamber (square cross-section side $l=2.55 \mathrm{~m}$ in this study) and have a square mesh (commonest), the area occupied by the screen wire can be calculated with the following equation;

$$
n_{w} l d_{w}+n_{w} l d_{w}-n_{w}\left(n_{w} d_{w}^{2}\right)
$$

Where, $d_{w}$ is the wire diameter, $n_{w}$ is the generic wire number in the mesh and $l$ is the settling chamber crosssection side. The last term in above equation takes into account the areas where the wires cross (black areas in Fig. 4).

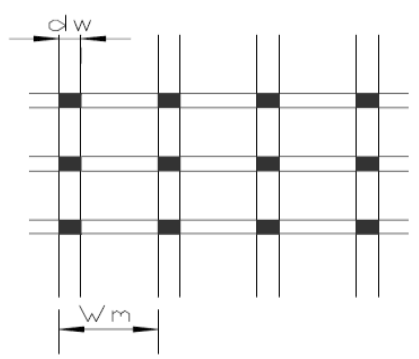

Figure: 4 Screen mesh sample

As in the honeycomb case, it is possible to calculate screen porosity using the following equation;

$$
\beta_{s}=\frac{A_{\text {flow }}}{A_{\text {total }}}=\frac{l^{2}-2 n_{w} l d_{w}+n_{w}^{2} d_{w}^{2}}{l^{2}}=1-2 n_{w} \frac{d_{w}}{l}+\frac{n_{w}^{2} d_{w}^{2}}{l^{2}}
$$

Simplifying the equation produces

$$
\beta_{s}=\left(1-\frac{n_{w} d_{w}}{l}\right)^{2}
$$

Screen mesh density is defined as the ratio between the mesh wire number and the cross section side of the chamber into which the screens are inserted [2]. The following equation defines the mesh density;

$$
\rho_{m}=\frac{n_{w}}{l}
$$

The mesh density inverse represents the screen mesh divisions $\left(w_{\mathrm{m}}\right)$ as shown in Fig. 4 and the following equation;

$$
w_{m}=\frac{1}{\rho_{m}}
$$

Taking screen mesh density into account, porosity can be written as-

$$
\beta_{s}=\left(1-d_{w} \rho_{m}\right)^{2}
$$

Table 2 shows the main screen characteristics for the case study. It also shows that the screen porosities for the two screens $\left(\mathrm{M}_{1}\right.$ and $\left.\mathrm{M}_{2}\right)$ verify the criterion $0.58 \geq \beta_{s} \leq 0.8$.

Table 2: Screen characteristics

\begin{tabular}{|l|l|l|l|l|}
\hline Description & Symbol & Unit & $\mathrm{M}_{1}$ & $\mathrm{M}_{2}$ \\
\hline Mesh wire diameter & $d_{w}$ & $\mathrm{~mm}$ & 0.58 & 0.45 \\
\hline Mesh divisions & $w_{m}$ & $\mathrm{~mm}$ & 2.50 & 1.95 \\
\hline Screen porosity & $\beta_{s}$ & - & 0.59 & 0.59 \\
\hline
\end{tabular}

\section{PRESSURE LOSSES}

In a wind tunnel, pressure losses occur as consecutive pressure losses in the different sections. Overall pressure loss $\left(\Delta p_{\text {global }}\right)$ equals the pressure gain due to the fan. In a wind tunnel component, $i$, pressure loss $\left(\Delta p_{i}\right)$ 
can be written as the product of constant $K_{i}$ and the dynamic pressure at the entrance of the component as shown in the following equation;

$$
K_{i}=\frac{\Delta p_{i}}{\frac{1}{2} \rho_{i} c_{i}^{2}}
$$

Where, $c_{i}$ is the mean flow velocity in the concerned section at the entrance of component $i$ [11].

With the above criteria, the loss coefficients for each wind tunnel component can be calculated. Table 3 shows pressure drops for each wind tunnel component. Summing all the wind tunnel section pressure drop values produces the total pressure drop.

Table 3: Component pressure loss at $c_{t s}=40 \mathrm{~m} / \mathrm{s}\left(c_{t s}=\right.$ test section air speed $)$
\begin{tabular}{|l|l|}
\hline Components & Pressure loss, $\Delta \mathrm{p}[\mathrm{Pa}]$ \\
\hline Test section & 9.76 \\
\hline Diffuser & 61.42 \\
\hline Honeycomb & 3.1 \\
\hline Screen 1 & 7.65 \\
\hline Screen 2 & 9.46 \\
\hline Contraction cone & 2.05 \\
\hline Total Pressure loss & 93.44 \\
\hline
\end{tabular}

Based on the loss coefficients and wind tunnel section pressure drops, and assuming a null relative pressure value in the testing section, the relative pressure values in the wind tunnel sections can be calculated (ideal, without energy loss see equation (12); real, with energy loss see equation (13)).

$$
\begin{gathered}
P_{\text {out }}-P_{\text {in }}=\frac{1}{2} \rho\left(u_{\text {in }}^{2}-u_{\text {owt }}^{2}\right) \\
P_{\text {out }}-P_{\text {in }}=\frac{1}{2} \rho\left(u_{\text {in }}^{2}-u_{\text {out }}^{2}\right)-\Delta P_{\text {loss }- \text { in -out }}
\end{gathered}
$$

Where, $\Delta P_{\text {loss-in- out is }}$ the pressure loss between inlet and outlet cross-sections of the component correlated to the $K_{i}$ factors.

Static pressure variation within the wind tunnel in ideal and real cases is reported in Fig. 5, while Fig. 6 shows incremental pressure loss.

Fig. 5 clearly shows lower pressure values in the real case compared to the ideal case up from test section to the fan section. From inlet to the honeycomb, the real pressure curve is always smaller than the ideal one which is due to the pressure losses throughout the wind tunnel.

The wind tunnel sections' contribution to pressure loss is shown in Fig. 7. Clearly most occurs in the diffuser section and minimum occurs in the contraction cone.

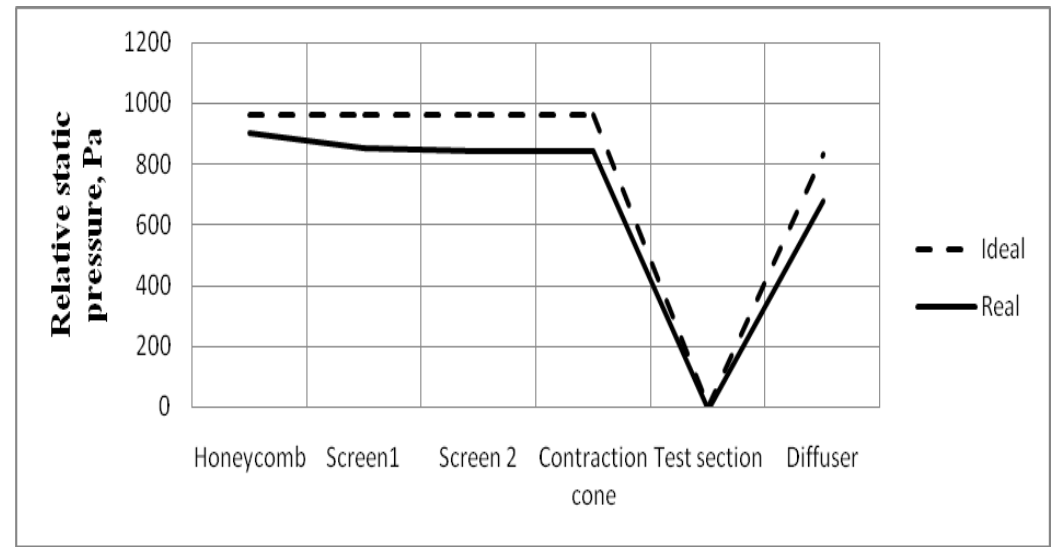

Figure: 5 Relative static pressure in the wind tunnel 


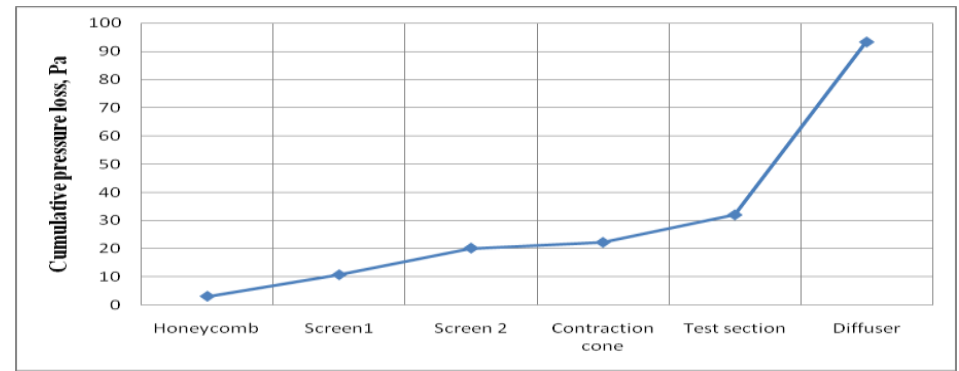

Figure: 6 Cumulative pressure losses in the wind tunnel

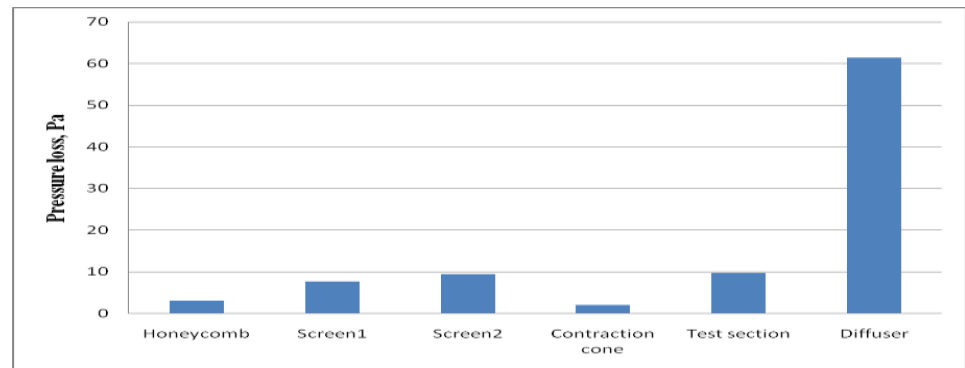

Figure: 7 Pressure losses in the wind tunnel

\section{Test Section}

\section{CONSTRUCTION}

The test section of the wind tunnel is constructed according to the design. The test section can be seen from the three sides i.e. front, back and top sides. For making the test section visible, acrylic sheet was used which is bolted to fix to the test section frame. An opening at the front side is provided to place the models into the test section easily. The leakages have been sealed with M-seal materials.

\section{Cone, Settling Chamber and Diffuser}

Contraction cone, settling chamber and diffuser have been constructed by $3 \mathrm{~mm}$ thick mild steel plate to minimize the construction costs. The most important thing is to fabricate the diffuser section since it has one end rectangular and other end circular.

\section{Honeycomb and Screens}

Two screens have been used in this wind tunnel to minimize the air turbulence and increase flow uniformity. Readymade screens were purchased from local market with necessary requirements. Honeycomb was made in the lab manually. For construction of honeycomb class-A PVC pipe was used. Fig. 8 shows the constructed honeycomb.

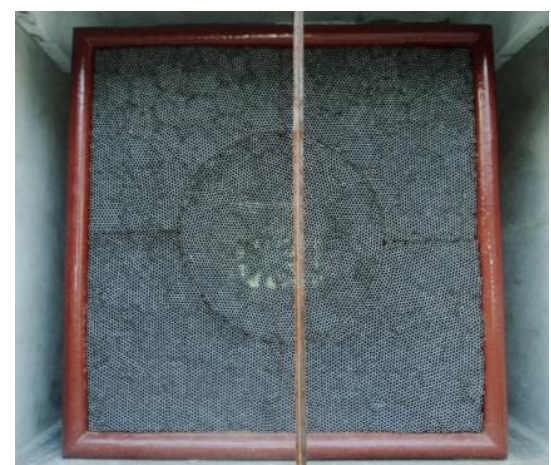

Figure: 8 Constructed honeycomb

\section{Assembled Wind Tunnel}

All sections of the wind tunnel were assembled and installed in the mechanical engineering workshop. Fig. 9 shows the installed wind tunnel after assembly. 


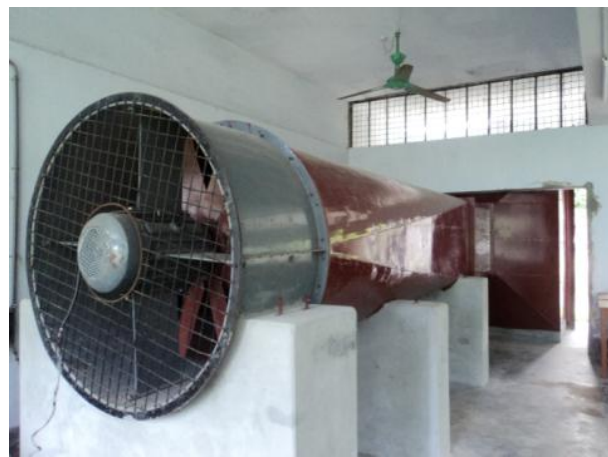

Figure: 9 fully fabricated wind tunnel

\section{RESULTS AND DISCUSSION}

After the construction of the wind tunnel component sections according to the design, the tunnel has been assembled and erected in the mechanical engineering workshop. Different data have been taken to construct the velocity profile in the test section and also the pressure readings at different point have been recorded. All data have been taken at maximum air velocity. Fig. 10 shows the horizontal velocity profile at different distance from the test section front wall while the data were taken midway of the test section.

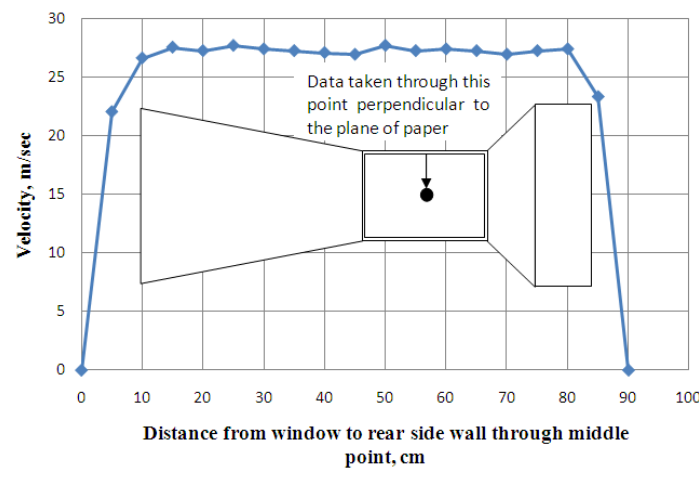

Figure: 10 Horizontal velocity profile

From horizontal velocity profile it can be seen that $10 \mathrm{~cm}$ from the rear front wall the velocity of flow is almost linear up to $80 \mathrm{~cm}$. Velocity near the wall is of gradually increasing nature this is because of the boundary layer. So, the maximum boundary layer thickness is found to be $10 \mathrm{~cm}$ and the effective air flow velocity is found in a length of $70 \mathrm{~cm}$ which is located $10 \mathrm{~cm}$ from the both wall. In percentage, the effective flow length is about $76 \%$ and boundary layer region in each wall is about $12 \%$ of the total width of the tunnel. The mean free stream velocity is found to be about $28 \mathrm{~m} / \mathrm{s}$.

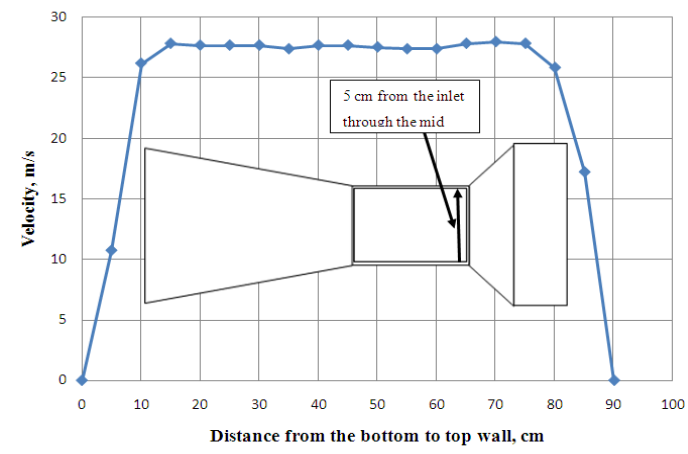

Figure: 11 Vertical velocity profile at a distance $5 \mathrm{~cm}$ from the test section inlet

Fig. 11 shows the vertical velocity profile at different distance from the bottom to top wall of the test section while the pressure difference reading was taken at a distance $5 \mathrm{~cm}$ from the test section inlet. Fig. 12 and Fig. 13 show the same while data were taken at a distance $60 \mathrm{~cm}$ and $115 \mathrm{~cm}$ from the test section inlet. 


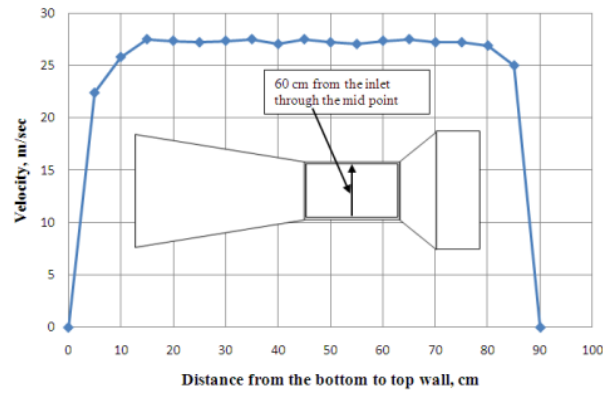

Figure: 12 Vertical velocity profiles at a distance $60 \mathrm{~cm}$ from the test section inlet

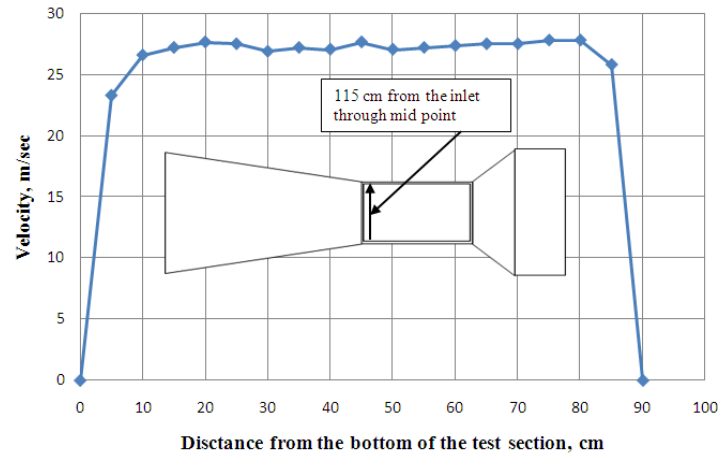

Figure: 13 Vertical velocity profiles at a distance $115 \mathrm{~cm}$ from the test section inlet

A plot was build up to show the vertical velocity profiles in combined form which is shown in Fig. 14 .

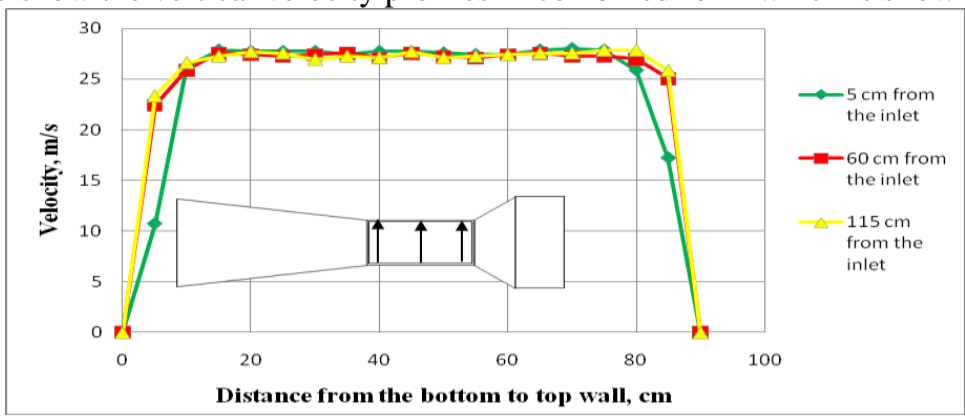

Figure: 14 Vertical velocity profiles at three positions

From the velocity profiles it is clear that the mean velocity in the test section is almost linear. At $5 \mathrm{~cm}$ from the test section inlet, air velocity close to the wall is much less than the other positions (at $60 \mathrm{~cm}$ and $115 \mathrm{~cm}$ ). The maximum velocity is also found at $5 \mathrm{~cm}$ position. These happen because of the effect of the contraction outlet due to which vena contracta is formed. In case of $60 \mathrm{~cm}$ and $115 \mathrm{~cm}$ positions, velocity profile is almost similar which indicates that mean flow velocity throughout the test section is identical. For all cases, velocity is gradually increasing near the wall because of the boundary layer formed. This boundary layer region is approximately $12 \%$ of the total height of the test section in each side.

So, the effective flow height is found to be approximately $76 \%$ of the total height of the test section. The effective flow region is $10 \mathrm{~cm}$ from the bottom wall to $10 \mathrm{~cm}$ below the top wall. In case of vertical measurements, the mean flow velocity in the effective flow region is about $28 \mathrm{~m} / \mathrm{s}$.

\section{CONCLUSION}

The purpose of this research work was to design, construct and performance test of a short length subsonic wind tunnel to verify its adequacy for aerodynamic analysis applications as well as to simulate the velocity profile at different position of the test section. The wind tunnel is designed considering a mean test section speed $40 \mathrm{~m} / \mathrm{s}$ and all factors are considered to make it as short as possible. Then, it is fabricated as accurately as possible.

The length of the constructed wind tunnel is about $7.35 \mathrm{~m}$ and a free stream velocity is found approximately $30 \mathrm{~m} / \mathrm{s}$. A comparison between the newly constructed wind tunnel and the wind tunnel built at NASA and MIT (USA) of approximately same test section is shown in table 4. From the comparison it is clear that the overall length of newly designed wind tunnel is much shorter than the other two. Besides this, the 
construction cost of the wind tunnel is about $\$ 8500$ which is much less than the one available in the market of the same size.

Table: 4 Comparison of newly designed wind tunnel with existing tunnels

\begin{tabular}{|l|l|l|l|}
\hline Parameters & New Tunnel & NASA(Small) Tunnel & MIT (USA) Tunnel \\
\hline Test section & $0.9 \mathrm{~m} \times 0.9 \mathrm{~cm}$ & $0.9 \mathrm{~m} \times 0.9 \mathrm{~m}$ & $0.85 \mathrm{~m} \times 0.85 \mathrm{~m}$ \\
\hline Mean velocity & $28 \mathrm{~m} / \mathrm{s}$ & $25 \mathrm{~m} / \mathrm{s}$ & $40 \mathrm{~m} / \mathrm{s}$ \\
\hline Test section length & $1.35 \mathrm{~m}$ & $3 \mathrm{~m}$ & $2.8 \mathrm{~m}$ \\
\hline Overall length & $7.35 \mathrm{~m}$ & $13 \mathrm{~m}$ & $11 \mathrm{~m}$ \\
\hline
\end{tabular}

Measurements of the velocity in the empty wind tunnel showed a uniform field which is essential for using it for aerodynamic researches. The detailed specifications of the constructed wind tunnel are shown in table 5.

Table: 5 Specifications of the newly designed wind tunnel

\begin{tabular}{|c|c|}
\hline Parameters & Value \\
\hline Type & Open circuit \\
\hline Test section length & $1.35 \mathrm{~m}$ \\
\hline Test section cross section & $0.90 \mathrm{~m} \times 0.90 \mathrm{~m}$ \\
\hline Mean air velocity range & $28 \mathrm{~m} / \mathrm{s}$ \\
\hline Overall length & $7.35 \mathrm{~m}$ \\
\hline Effective region in the test section & $76 \%$ of width or height \\
\hline Boundary layer region & $8 \%$ of width or height from every wall \\
\hline Contraction ratio & $0.02 \mathrm{~m}, 0.125 \mathrm{~m}$ \\
\hline Honeycomb cell diameter, length & 2 \\
\hline Number of screens & $2.55 \mathrm{~m} \times 2.55 \mathrm{~m}$ \\
\hline Settling chamber cross section & 3-phase $20 \mathrm{~kW}, 10$ blades \\
\hline Motor and Fan & \\
\hline
\end{tabular}

The new designed tunnel is, therefore, a very good device to provide parallel steady flow with uniform speed through the test section without excessive turbulence and can be used effectively in different aerodynamic researches.

\section{ACKNOWLEDGEMENTS}

With deep sincerity, the author express profound gratefulness to Prof. Dr. Mohammad Mashud, Head, Department of Mechanical Engineering, Khulna University of Engineering \& Technology (KUET), for his guidance and valuable counsel in execution and completion of the study.

\section{REFERENCES}

[1] Harold Sherwood Boudreau III, "Design, construction, and testing of an open atmospheric boundary layer wind tunnel", a dissertation presented to the undergraduate school of the university of Florida, 2009

[2] William H. Rae, JR., Alan Pope, “Low Speed Wind Tunnel Testing”, Second edition, 1984.

[3] Ben Goldberg \& Tom Carlone, "Building a Wind Tunnel: It will blow your mind", A project report submitted to university of Florida, May 2008.

[4] Worthey, "Subsonic Wind Tunnels", The Wind tunnel Connection, 23 June 2006.

[5] Nathan Tatman, "Wind Tunnel Design and Operation", a thesis paper submitted for undergraduate degree, 2008.

[6] J.E. Sargison, G.J. Walker and R. Rossi, "Design and calibration of a wind tunnel with a two dimensional contraction", $15^{\text {th }}$ Australasian fluid mechanics conference, The University of Sydney, Sydney, Australia, December 2004.

[7] "Going with the flow, Aerospace Engineering \& Manufacturing, pp. 27-28, Society of Automotive Engineers", March 2009.

[8] Seth and Modi, "Hydraulics and Fluid Machinery", $4^{\text {th }}$ Ed. McGraw Hill, New York.

[9] Pankhurst, R. C. \& Holder D. W., “Wind Tunnel Technique”, Sir Isaac Pitman \& Sons Ltd, 1952,

[10] Goce Talev, Arild Gustavsen, Jan Vincent Thue, "Experimental Confirmation on the Theoretical Model for the Velocity Profile in a Rectangular Wind Tunnel".

[11] S. Brusca, R. Lanzafame and M. Messina, "Low-speed wind tunnel: design and build", In: Wind Tunnels: Aerodynamics, Models and Experiments, 2011.

[12] Bradshaw P, Mehta RD., "Design rules for small low speed wind tunnels", The Aeronautical Journal of the Royal Aeronautical Society, November 1979. 
[13] J. M. Robertson and H. R. Fraser, "Separation Prediction for Conical Diffusers", Transactions ASME, Series D82, 201, 1960.

[14] Bell J. H., Metha R. D., "Contraction Design for Small Low-Speed Wind Tunnels”, NASACR- 182747, April 1988.

[15] Prandtl L., "Attaining a Steady Stream in Wind Tunnel”, NACA TM 726, Oct. 1933.

[16] Bradshaw, P. \& Pankhurst, R. C., "The design of low-speed wind tunnels progress in aeronautical sciences", 6, 1-69, 1964.

[17] Björn Lindgren \& Arne V. Johansson, "Design and Evaluation of a Low-Speed Wind-Tunnel with Expanding Corners", Technical Reports from Royal Institute of Technology Department of Mechanics SE-100 44 Stockholm, Sweden, October 2002.

[18] Shames I. H., "Mechanics of Fluids", 3rd Ed. McGraw Hill, New York, 1992.

[19] Eckert W., Mort K. W. - Pope J. "Aerodynamic Design Guidelines and Computer Program for Estimation of Subsonic Wind Tunnel Performance", National Aeronautics and Space Administration NASA TN D-8243, Washington, D.C, October, 1976.

[20] Idel'chick I. E. "Handbook of Hydraulic Resistance", The Israel Program for Scientific Translation, Tel Aviv, AECTR-6630, 1966.

[21] Wattendorf F. L., "Factors Influencing the Energy Ratio of Return Flow Wind Tunnels", Fifth International Congress for Applied Mechanics, Cambridge, 12-16, September 1938.

[22] T. Morel, "Comprehensive Design of Axisymmetric wind Tunnel Contractions", J. Fluids Engineering, ASME Transactions, 225-233, June 1975

[23] G. G. borger, "The Optimization of Wind Tunnel Contractions for the Subsonic Range", NASA TTF 16899, March 1976.

[24] M. N. Mikhail and W. J. Rainbird, "Optimum Design of Wind Tunnel Contractions", Paper 78-819, AIAA 10 Aerodynamic Testing Conference, PP. 376-384, 1978. 